\title{
Reading Programs and the Junior College Library*
}

Miss Newman is director of Reading Program, and Mr. Peskind, assistant librarian and audio-visual director, 'Wright Junior College, Chicago.

Cooperation between the library and 1 the academic departments in a junior college is essential to the most effective functioning of both groups. When a new program or course is established it is generally recognized that the library has the responsibility for providing appropriate services and materials. In the case of a newly instituted reading program, the library has additional obligations of its own. A library is, among other things, a center of reading materials and a place to read. The library, informally or otherwise, has an inherent interest in reading and in all of the problems concerned with reading. The Wright Junior College Library is very much involved in the growth of the reading program as it is believed that academic library personnel should be constantly aware of the reading problems of students, and participate as fully as possible in their solution. In many institutions the library and reading programs are very effectively integrated. The example with which we shall primarily concern ourselves is an instance of such cooperation. It may be noted that the term reading program is used to designate any formal arrangement within institutions of any variety which provides

* Paper given at ACRL Junior College Libraries Section meeting, Feb. 5, 1953, Chicago. training by which individuals may become more efficient readers.

When the reading program first came upon the scene in higher education many persons saw it only as a tool to help the student who was seriously retarded in the development of a fundamental skill. Now, in many instances, reading programs have been formulated with the purpose of serving all the students at their current reading levels. At Wright Junior College in Chicago there is such a program. Wright is a two-year public college where students follow terminal studies and also prepare for work on a more advanced academic level. Wright is also a community college. As an aspect of community service a course in Reading Improvement is offered as a part of the Adult Education program. Another similar but extended service is available to persons who are enrolled in the Police Training Program.

There is a three-level reading service for regular students. Attention to individual reading problems is given in Reading Workshops which are non-credit groups. Materials which are used in this work are selected in accordance with the students' current reading level. A course in Developmental Reading is designed to serve the average student reader. Here, the material is all on college level since two hours credit is given for this course. The Analytical Reading course provides challenging reading situations for students who are already excellent readers. Reading matter in this 
course is selected from the areas of general education: sciences, social sciences, and the humanities. Some mechanical equipment such as tachistoscopes and reading accelerators is incorporated into the reading program in various ways in accordance with the objectives of the courses and needs of the students.

An academic library should be prepared to provide materials and services for all courses and phases of the curriculum. If a reading program is started in a school, the library is obligated to provide for it much in the same way that it would for a new course in English, chemistry, or in history. At the very beginning, existing resources should be examined for their applicability and usefulness to the new reading courses. If present facilities in the library cannot handle the new situations, then the guiding rule should be that new materials and services must be provided to meet the situation.

After one semester of an experimental reading program in the non-credit adult education evening classes at Wright Junior College, it was decided that a complete reading program should be initiated for the entire college. At the very beginning, the reading instructors conferred with the librarian to make known the needs of the new program. The librarian then proceeded to organize library resources to aid the reading instructors and students.

In the organizational set-up of the library at Wright, the librarian is in charge of professional reading resources for the faculty as well as the library staff. To accommodate the new reading program, the librarian began a systematic search through books, periodical articles, newspaper accounts, and other materials of value for the reading instructors. This information of a professional nature is sent to the instructors as a part of the library's program of service to the faculty.

An assistant librarian is assigned to be in charge of supplies which are used by reading students. This librarian scans book catalogs, lists, trade bibliographies, and other sources to find reading materials which are graded and texts that are specifically designed for remedial reading or are otherwise well suited to the $W$ right reading program.

This concern for appropriate materials has led to a certain amount of reorientation in book selection procedures. The student with reading difficulties was recognized and accepted for the first time and adjustments were accordingly made in the book collections. An example of an adjustment to reading has occurred at the request of the reading instructors themselves when the World Book Encyclopedia was added to the reference collection. Other reference works of a simplified nature were acquired to meet the needs of students who, although they have difficulties in reading, may be very intelligent and serious about their studies. Evaluation and change in book selection has occurred as a result of the new reading consciousness of teaching departments in the junior college. Requests for books from departments now typically contain a few books of excellent quality which are geared at lower levels of reading difficulty.

All the departments of the library have been drawn into the reading program in one respect or another. The reference librarian and the cataloger-order librarian both assume responsibilities for reading materials just as they do for other materials. As the Wright Library has a rather well-developed audio-visual section, it, too, is integrated into the reading program. Reading accelerators are housed in the library adjacent to the audio-visual room and convenient to 
electrical outlets and supervision by the audio-visual librarian. Students are assigned by the reading instructors to use the accelerators on an individual basis. There is a special collection of books on the tables with the accelerators and recommended for use with them. These books were chosen by the reading instructors for their reading content and have word counts in them so that rates on the accelerators can be immediately determined by the students without computation.

The audio-visual department also provides mechanical maintenance for the accelerators as well as for the tachistoscopes, ophthalmographs, and other devices used in the reading classes. The library dispatches student operators to deliver this equipment to instructors so that it is set up and ready for immediate use. The reading instructors and the audio-visual librarian work very closely together to work out problems involving technical equipment and audiovisual materials.

Though the library has already adapted its resources and abilities to the new reading program, it plans to expand its services. As the reading program becomes more extensive, the library services will undoubtedly become greater and more varied to meet the new demands of the program. The library has formulated plans for increased reading activities including a separate area for reading students which will be equipped with accelerators, special books, materials, and other devices.

The school or college library will probably make its greatest contribution to the expanded interest in reading by performing its usual function of directly integrating itself with the teaching program. When new courses, workshops and other curriculums concerned with reading are instituted, the academic library will play a role as important as those which it plays in traditional courses and academic activities. Only by constantly adapting itself to school and college needs, can the library continue to perform its basic educational function.

\section{Prompt Payment of Bookdealers' Invoices}

\section{(Continued from page 392)}

ards depends upon the incorporation of a tolerance factor. Standards might then be stated in some such terms as these: "If a university library processes $85 \%$ of all invoices within ten days and the remainder within a month, its performance may be adjudged highly satisfactory."

\section{Conclusion}

Implicit throughout this discussion is the premise that promptness in processing fayment for library materials is essential to the maintenance of strong, cordial relationships between dealers and libraries. Motivated by a desire to promote mutual understanding between partners in an enterprise of considerable importance to academic communities, an attempt has been made to explore the possibility of constructing standards acceptable to both.

An analysis of Columbia University $\mathrm{Li}$ braries' performance in this area indicates that the standards tentatively evolved may be applicable to a majority of university libraries in the U.S. Their general applicability and adoption, however, must wait upon reports of library investigations other than the one reported here.

A separate analysis of invoices requiring longer than ten days to process suggests (I) that dealers' expectations do not take fully into account certain factors which are not subject to effective control, and (2) that the practicability of any adopted standards depends upon the incorporation of a realistic tolerance factor. 